\title{
SENTENCIA SOBRE AMPARO DE DERECHOS FUNDAMENTALES (TRIBUNAL CONSTITUCIONAL)
}

\author{
Comentario de Eduardo Aldunate Lizana
}

Pontificia Universidad Católica de Valparaíso

Santiago, treinta y uno de agosto de dos mil siete.

VISTOS:

Con fecha 19 de marzo de 2007, María Isabel Reyes Kokisch ha formulado una acción de inconstitucionalidad en contra del Auto Acordado Relativo al Procedimiento a Utilizarse para hacer Efectiva la Responsabilidad Disciplinaria de los Funcionarios y Empleados Judiciales, dictado el 13 de octubre de 1995 por la Corte de Apelaciones de Santiago y publicado en el Diario Oficial de 17 de noviembre de 1995 (en adelante, el Auto Acordado).

Señala la requirente que tal cuerpo normativo infringe los artículos $7^{\circ}$, incisos segundo y tercero, $19 \mathrm{~N}^{\circ} 2^{\circ}, \mathrm{N}^{\circ} 3$, incisos primero, segundo, cuarto y quinto, y $\mathrm{N}^{\circ} 26$; 63 , inciso primero, $\mathrm{N}^{\text {os. }} 1,2,3$ y 20; 64, inciso segundo, 76, 77, inciso primero, $\mathrm{y}$ $8^{\circ}$, inciso segundo, todos de la Constitución Política. Además, vulnera el artículo $8^{\circ}$, $\mathrm{N}^{\circ} 1, \mathrm{~N}^{\circ} 2$, letras c), f) y h), y $\mathrm{N}^{\circ} 5$, y el artículo 25, todos del Pacto de San José de Costa Rica.

(...)

\section{CONSIDERANDO:}

I. Cuestiones de constitucionalidad a resolver y explicitación de dos criterios generales con que se abordará el examen.

PRIMERO. Que, temáticamente sistematizados, los reproches de constitucionalidad que la requirente dirige al Auto Acordado de la Corte de Apelaciones de Santiago "Relativo al Procedimiento a Utilizarse para Hacer Efectiva la Responsabilidad Disciplinaria de los Funcionarios y Empleados Judiciales”, de fecha 13 de octubre de 1995, publicado en el Diario Oficial de 17 de noviembre del mismo año (en adelante, el Auto Acordado), pueden ser agrupados en seis:

I. El primero consiste en impugnar las normas del Auto Acordado por no garantizar a su defendida un justo y racional procedimiento. Al efecto, alega:

1. que ellas otorgan una múltiple función investigadora, acusadora y de dirección del probatorio a un mismo juez, por lo que establecen un tribunal que 
no puede ser considerado imparcial, sino una comisión especial de aquellas que repugnan a la Carta Fundamental;

2. también funda la falta de un justo y racional procedimiento en que otros preceptos del Auto Acordado impiden que se pueda tener una defensa que cuente con el tiempo y los medios adecuados para su preparación y desarrollo;

3. alega en tercer lugar que no se contemplan, en ese cuerpo, medios de impugnación suficientes en contra de lo que recomienda o resuelve el instructor.

La requirente funda este primer capítulo de inconstitucionalidad en la noción de debido proceso y en su consagración positiva en el inciso quinto del numeral $3^{\circ}$ del artículo 19 de la Carta Fundamental y en el artículo $8^{\circ}$, números 1,2 , letras c), f) y h), y 5 y artículo 25 del Pacto de San José de Costa Rica.

II. En segundo lugar, la requirente impugna algunos preceptos del Auto Acordado por consagrar con carácter secreto la investigación destinada a indagar y la audiencia llamada a decidir los cargos disciplinarios que se le imputan, lo que, a su juicio, violenta las garantías de un justo y racional proceso y la debida transparencia de los actos públicos, consagrados respectivamente en el artículo $19, \mathrm{~N}^{\circ} 3$, inciso quinto, y artículo $8^{\circ}$ de la Constitución, así como en el artículo $8^{\circ} \mathrm{N}^{\circ} 5$ del Pacto de San José de Costa Rica.

III. En tercer lugar, reprocha al Auto Acordado haber sido dictado por la Corte de Apelaciones, la que, según alega, carece de competencia para dictarlo con ese contenido, pues ni la Constitución ni la ley le atribuyen tal facultad, por lo que, al hacerlo, ha excedido su competencia y, con ello, ha vulnerado el artículo $7^{\circ}$ de la Carta Fundamental.

IV. Un cuarto reproche consiste en que el Auto Acordado ha regulado una materia que la Carta Fundamental reserva al legislador y, más precisamente, al legislador orgánico constitucional. Funda este aserto en varias razones:

1. En primer lugar, en que el Auto Acordado afecta derechos fundamentales, lo que no puede hacerse sino por ley, conforme a lo dispuesto en el numeral 26 del artículo 19 de la Carta Fundamental;

2. En segundo lugar porque se trata de fijar un procedimiento legal para un órgano que ejerce jurisdicción, lo que está reservado por la Carta Fundamental sólo al legislador, conforme lo dispone el numeral $3^{\circ}$ de su artículo 19; y

3. En tercer lugar, porque el cuerpo normativo impugnado regula materias relativas a la organización y atribuciones de los Tribunales de Justicia, lo que sólo puede hacer el legislador orgánico constitucional, conforme a lo dispuesto en el artículo 77 de la Constitución.

Para reforzar cada una de estas peticiones invoca también lo dispuesto en los numerales $1^{\circ}, 2^{\circ}, 3^{\circ}$ y $20^{\circ}$ del artículo 63 , que reservan al legislador la regulación de materias que la requirente alega incluidas en el Auto Acordado.

V. El quinto motivo de impugnación que la requirente dirige al Auto Acordado es el de violar el principio de igualdad ante la ley, consagrado en el numeral $2^{\circ}$ del artículo 19 de la Constitución, pues establece una diferencia arbitraria, ya que el resto de los trabajadores están sometidos a normas legales en cuanto al régimen 
disciplinario que rige su situación laboral, mientras sólo los funcionarios judiciales quedan sujetos a una norma de inferior jerarquía, como lo es un auto acordado.

VI. Por último, y en sexto lugar, la requirente alega que, al seguirse en su contra una acción disciplinaria con esos vicios, se ha vulnerado su derecho a la integridad psíquica, que asegura a toda persona el numeral $1^{\circ}$ del artículo 19 de la Carta Fundamental.

SEGUNDO. Que, aun cuando en la parte petitoria se solicita la declaración de inconstitucionalidad de todo el Auto Acordado, los dos primeros reproches consignados en el considerando anterior se dirigen necesariamente en contra de determinados preceptos del mismo, mientras los cuatro finales se dirigen en contra del Auto Acordado como un todo.

TERCERO. Que la facultad de esta Magistratura para conocer de la petición de la requirente le ha sido conferida por el numeral $2^{\circ}$ del artículo 93 de la Carta Fundamental, que atribuye al Tribunal Constitucional la competencia para "resolver las cuestiones de constitucionalidad de los autos acordados dictados por ... las Cortes de Apelaciones...”. Siendo ésta la primera oportunidad en que este Tribunal dicta sentencia definitiva en un requerimiento declarado admisible que se dirige en contra de un auto acordado, resulta conveniente explicitar dos aspectos relativos al alcance del examen que se practicará.

CUARTO. Que el artículo 93, número $2^{\circ}$, de la Constitución, que atribuye a esta Magistratura competencia para resolver la constitucionalidad de un auto acordado, se refiere a las normas a examinar en términos genéricos o abarcadores del cuerpo normativo como un todo. Estos términos genéricos o abarcadores de todo el cuerpo legal a revisar resultan análogos a los que la Constitución emplea al dar competencia a este Tribunal para pronunciarse acerca de la constitucionalidad de otros tipos de normas "Ejercer el control de constitucionalidad de las leyes que interpreten algún precepto de la Constitución (o) de las leyes orgánicas constitucionales...”, según reza el numeral $1^{\circ}$ del artículo 93; lo mismo ocurre con la facultad que le otorga el numeral $3^{\circ}$ del propio artículo para "resolver las cuestiones sobre constitucionalidad que se susciten durante la tramitación de los proyectos de ley o de reforma constitucional y de los tratados sometidos a la aprobación del Congreso;". El mismo modo genérico y abarcador para referirse al cuerpo legal impugnado emplean los numerales $4^{\circ}, 9^{\circ}$ y $16^{\circ}$ del mismo artículo 93 al aludir al control de constitucionalidad de los decretos con fuerza de ley y de los decretos supremos. Como puede apreciarse de las normas transcritas, la Constitución, en todos los casos referidos, al igual como hizo la reforma de 2005 con los autos acordados, alude a cuerpos normativos en general y no a preceptos determinados de ellos, como sí hace en el caso de los tratados internacionales y de la inaplicabilidad de preceptos legales. En los casos de todos los cuerpos normativos mencionados, esta Magistratura ha entendido siempre que lo que le corresponde es invalidar tan sólo los determinados preceptos de un cuerpo normativo que efectivamente adolezcan de vicios de inconstitucionalidad, pero sin que 
ello afecte la validez de las restantes normas contenidas en ese mismo cuerpo normativo, a menos que la inseparable ligazón entre las que adolecen de inconstitucionalidad y el resto sea tal que ninguna de las restantes pueda subsistir sin aquéllas.

QUINTO. Que este Tribunal mantendrá ese criterio en el examen del Auto Acordado cuestionado de inconstitucionalidad. Desde luego, porque, como se ha dicho, la consagración de esta facultad es análoga para todas las clases de normas legales o de proyectos de ellas que son susceptibles de ser declaradas inconstitucionales, según se razona en el considerando 4 que antecede. En segundo lugar, porque la posibilidad de que sólo una parte del cuerpo normativo sea declarada inconstitucional, sin afectar al resto, se encuentra claramente contemplada por igual para las leyes, los decretos con fuerza de ley, los decretos supremos o los autos acordados al establecer la Constitución, en el inciso final de su artículo 94, que las sentencias que declaren “...la inconstitucionalidad de todo o parte ..." de los cuerpos normativos señalados, deberán publicarse en el Diario Oficial en un plazo determinado. En tercer lugar, por congruencia con su línea jurisprudencial y la seguridad que su continuidad acarrea. En cuarto lugar, por apego al principio de igualdad ante situaciones análogas, ya que no avizora diferencia alguna para variar el criterio que aplica cuando revisa otros cuerpos normativos, cuyo control de constitucionalidad le ha sido encomendado en términos análogos a aquel que ahora le compete en materia de autos acordados. Pero, más importante, porque el criterio de declarar inconstitucionales tan sólo los preceptos que efectivamente adolecen de vicio de inconstitucionalidad permite mantener la vigencia de normas válidamente emitidas que no se ven afectadas por él. El bien común de la sociedad exige de la actividad estatal; por ello, todo el producto de la actividad normativa del Estado merece subsistir, a menos que adolezca de vicios que ameriten su inconstitucionalidad. En consecuencia, así como es un deber de esta Magistratura, en el ámbito de su competencia y en la forma prescrita por la Constitución, inaplicar o dejar sin efecto las normas contrarias a la Carta Fundamental, es también su deber no hacerlo ni impedir que nazcan a la vida del derecho aquellas que no adolezcan de tales vicios.

SEXTO. Que la Carta Fundamental sólo otorga legitimación activa a una parte para recurrir en contra de un auto acordado "cuando sea afectada en el ejercicio de sus derechos fundamentales por lo dispuesto en el respectivo auto acordado", conforme lo establece el inciso tercero de su artículo 93. En consecuencia y a propósito de un requerimiento, a esta Magistratura sólo le corresponde examinar la constitucionalidad de aquellos preceptos del Auto Acordado que tengan la aptitud de afectar el ejercicio de derechos fundamentales de la requirente. El Auto Acordado impugnado contiene preceptos que no tienen esa aptitud, muchos de los cuales simplemente no pueden aplicarse a la requirente, como aquél contenido en la letra e) de su numeral $4^{\circ}$, que permite, como medida preventiva, suspender en el cargo o trasladar al personal de Secretaría.

SÉPTIMO. Que los criterios expuestos en los tres considerandos que anteceden obligarán a esta Magistratura a hacer un examen no del Auto Acordado como un todo, 
sino de sus diversos preceptos, excluidos aquellos que no tienen aptitud para afectar el ejercicio de derechos fundamentales de la requirente, $y$, en caso de concluir que existe un vicio de constitucionalidad, a determinar el o los preceptos del cuerpo normativo que efectivamente son alcanzados por el vicio.

OCTAVO. Que, en el evento de concluirse que, en virtud de alguna de las razones invocadas, un precepto del Auto Acordado es contrario a la Carta Fundamental, se hará innecesario analizar otras causales de inconstitucionalidad alegadas para el mismo precepto. Este modo de razonar, ya asentado en nuestro medio jurídico, se sustenta en el hecho de que, respecto de este requerimiento, resulta innecesario e inútil entrar a considerar si un precepto, cuya inconstitucionalidad ya se ha concluido por contradecir una norma constitucional, debe ser declarado inconstitucional además por ser contrario a otro precepto de la misma Carta.

\section{El Auto Acordado y la falta de un debido proceso}

NOVENO. Que, como se ha dicho, la requirente solicita la inconstitucionalidad del Auto Acordado alegando que sus normas no garantizan un justo y racional procedimiento. Este reparo se funda en tres causales: la primera, que procederemos a analizar en los considerandos que siguen, es que el procedimiento no sería ni racional ni justo, pues el mismo juez que instruye la investigación está llamado a formular los cargos, a proponer las sanciones que estime procedentes y a dirigir la etapa probatoria, con facultades de desechar o aceptar probanzas. A juicio de la requirente, esta confusión de tareas en un mismo juez conlleva establecer un tribunal que no puede ser considerado imparcial, sino una comisión especial de aquellas que repugnan a la Carta Fundamental. Funda esta causal en lo preceptuado en el artículo 19, $\mathrm{N}^{\circ} 3$, de la Constitución, específicamente en su inciso cuarto, que prohíbe el juicio por comisiones especiales, y en el numeral $1^{\circ}$ del artículo $8^{\circ}$ del Pacto de San José de Costa Rica, en cuanto obliga a que las personas sean juzgadas por jueces imparciales.

DÉCIMO. Que esta primera alegación sólo puede entenderse dirigida en contra de las normas contenidas en el número $4^{\circ}$, letras h) e i), del Auto Acordado, pues son ellas y no otras de ese cuerpo normativo las que consagran esta multiplicidad de tareas. El primero de los preceptos citados dispone que "el investigador, junto con señalar los cargos contra el o los inculpados, propondrá al Juez las sanciones que estime procedente aplicarle"; mientras en la letra i) se dispone que el imputado podrá presentar descargos o defensas y solicitar y presentar pruebas. Aunque esta última norma no indica expresamente ante quién se rinde la prueba, al no contemplarse otro sujeto, ella implícitamente supone que se rinda ante el mismo funcionario investigador. Así ha ocurrido en la gestión pendiente que motiva el requerimiento.

(...) 
DÉCIMO SEGUNDO. Que no resulta contrario a la justicia ni a la racionalidad que un mismo funcionario que instruye un sumario disciplinario de otro funcionario del mismo escalafón judicial (en la especie, un Ministro de Corte de Apelaciones en relación a un Secretario de Juzgado) dirija la investigación, establezca los cargos, reciba la prueba de descargo y proponga sanciones, ni menos que tal confusión de tareas en un mismo órgano lo transforme por ello en una "comisión especial". La imparcialidad es una cualidad que cabe exigir, aunque de diversa forma, de quien juzga y de quien investiga. Respecto del juzgador debe destacarse que, conforme al Auto Acordado, quien juzga no investiga ni formula cargos. Conforme al Auto Acordado, al investigador sólo le corresponde proponer las sanciones, mas no decidirlas; la decisión o juicio corresponde a aquel que el Auto Acordado denomina como juez en las letras k) y l) de su acordado $4^{\circ}$. En consecuencia, el reproche de parcialidad del tribunal no alcanza al tribunal propiamente tal.

DÉCIMO TERCERO. Que al investigador de un sumario, por su parte, cabe exigirle también imparcialidad, particularmente en el celo que ponga en indagar tanto lo que favorece como lo que desfavorece a aquel en contra de quien se han formulado cargos, pero esta imparcialidad no se pierde por el solo hecho de que el investigador formule cargos. Esta misma doble asignación de las tareas de investigar y formular cargos en un mismo funcionario es la que el legislador ha establecido para los sumarios administrativos, sin que esta Magistratura se haya enterado o el requirente le haya informado que esta situación haya sido considerada inaceptable por la doctrina respectiva. Tampoco es contrario a la imparcialidad que ese mismo investigador proponga, de un modo no vinculante, la aplicación de sanciones. Lo dicho no quiere decir que un sistema que distinga estas tareas de investigar y proponer cargos no pueda considerarse más perfecto para alcanzar mayor imparcialidad y justicia. Sólo afirma que el que existe no repugna tales principios en términos suficientes para declararlo inconstitucional.

DÉCIMO CUARTO. Que por los mismos motivos indicados en los dos considerandos que anteceden, también debe concluirse que el hecho de que el investigador que formula cargos tenga asimismo la facultad de dirigir la producción de la prueba no repugna, por sí solo, la racionalidad o la justicia de un proceso o de la investigación que le precede; máxime si se tiene presente que, en conformidad a lo dispuesto en la letra 1) del numeral $4^{\circ}$ del Auto Acordado, el juez, antes de resolver "podrá ordenar la realización de nuevas diligencias o la corrección de vicios de procedimiento, fijando un plazo para tales efectos". Entre esas actuaciones susceptibles de corrección naturalmente pueden estar aquellas resoluciones del investigador que hayan decretado o negado diligencias probatorias.

DÉCIMO QUINTO. Que, por lo razonado en los considerandos 9 a 14 que anteceden, no cabe declarar inconstitucional, por este reproche lo dispuesto en las letras h) e i) del número $4^{\circ}$ del Auto Acordado. 
DÉCIMO SEXTO. Que la requirente también funda su reproche de que el procedimiento establecido en el Auto Acordado no es ni justo ni racional, en razón de que en él se impide a su parte tener una defensa que cuente con el tiempo y los medios adecuados para su preparación y desarrollo. Funda este aserto en dos alegaciones: en el carácter secreto de la investigación y en que el plazo para responder los cargos y oponer defensas y solicitar y presentar pruebas es tan sólo de cinco días, lo que no permite una adecuada defensa. A juicio de la requirente, esos preceptos vulneran las normas constitucionales ya referidas que aseguran las garantías de un justo y racional procedimiento, así como el inciso segundo del numeral $3^{\circ}$ del artículo 19 de la Carta Fundamental, en cuanto garantiza el derecho a la defensa, y también el derecho a defensa, del modo establecido en el artículo $8^{\circ}$ del Pacto de San José de Costa Rica. Este reproche sólo puede ser dirigido en contra de lo prescrito en la letra d) del número $4^{\circ}$ del Auto Acordado, en cuanto dispone que "el sumario administrativo será reservado hasta la fecha de formulación de cargos, oportunidad en la cual dejará de serlo para el inculpado y para el abogado que asumiere su defensa", y en contra de lo dispuesto en la letra i) del mismo artículo, que establece el plazo de 5 días para presentar descargos o defensas y solicitar y presentar pruebas. Tales reproches simplemente no alcanzan a las restantes normas del Auto Acordado, pues ellas establecen reglas que nada tienen que ver con el reproche que ahora se examina.

DÉCIMO SÉPTIMO. Que el carácter reservado de la investigación sumarial sólo está dispuesto en la letra d) del numeral $4^{\circ}$ del Auto Acordado, pues no lo establecen así los preceptos legales contenidos en el Título XVI del Código Orgánico de Tribunales, que se refieren a la jurisdicción disciplinaria. Por su parte, el inciso segundo del artículo $8^{\circ}$ de la Constitución, en resguardo del principio de probidad, establece que "son públicos los actos y resoluciones de los órganos del Estado, así como sus fundamentos y los procedimientos que utilicen...", agregando que "... sólo una ley de quórum calificado podrá establecer la reserva o secreto de aquéllos o de éstos, .....". Si bien el artículo $4^{\circ}$ transitorio de la Carta Fundamental valida las leyes ordinarias vigentes con anterioridad a su entrada en vigor que se refieran a materias reservadas por el constituyente a las de carácter orgánico constitucional o de quórum calificado, no hace otro tanto con los Autos Acordados que regulen esas materias. Por ende, la contradicción de la norma impugnada con la Carta Fundamental se hace evidente con el solo contraste de la literalidad de ambos preceptos, pues mientras el de rango inferior, la letra d) del número $4^{\circ}$ del Auto Acordado establece una reserva absoluta del sumario administrativo -el que se compone de actuaciones y resoluciones de un órgano del Estado-, reserva que alcanza incluso al funcionario sujeto a investigación, el precepto de mayor jerarquía, contenido en el artículo $8^{\circ}$ de la Carta Fundamental, dispone la publicidad de los procedimientos y resoluciones de los órganos del Estado, salvo que el secreto sea dispuesto por una ley de quórum calificado, fundada en las razones que la propia Constitución establece, lo que no ocurre en la especie.

DÉCIMO OCTAVO. La conclusión a que se arriba en el motivo que antecede es suficiente para concluir que lo dispuesto en la letra d) del numeral $4^{\circ}$ del Auto Acordado 
es contrario a la Carta Fundamental y así se declarará. Tal conclusión, conforme a lo razonado en el considerando 8 de esta sentencia, hace innecesario el análisis de los otros vicios de inconstitucionalidad que la requirente atribuye a ese precepto, al igual que resulta inoficioso el examen de la pugna entre el mismo precepto del Auto Acordado y normas contenidas en el Pacto de San José de Costa Rica.

(...)

VIGÉSIMO. Que, por último y también invocando las normas constitucionales y de derecho internacional relativas al derecho a la defensa, la requirente ha impugnado la validez del Auto Acordado en cuanto no establece recursos efectivos en contra de las resoluciones que se adopten en los sumarios destinados a hacer efectiva la responsabilidad disciplinaria y, particularmente, porque no contempla la posibilidad de recurrir de apelación en contra de las resoluciones que denieguen determinadas actuaciones probatorias, como alega que se le han negado en la gestión disciplinaria que se sigue en su contra. La requirente funda este capítulo de inconstitucionalidad en la noción de debido proceso y en su consagración positiva en el inciso quinto del numeral $3^{\circ}$ del artículo 19 de la Carta Fundamental y en el artículo $25 \mathrm{~N}^{\circ} 1$ del Pacto de San José de Costa Rica. Este reproche no se dirige contra preceptos determinados de ese cuerpo normativo y no podría hacerlo, porque no hay disposiciones en el Auto Acordado que limiten el recurso de apelación. La contenida en la letra o) de su acordado $4^{\circ}$ concede derecho de apelación en contra de medidas disciplinarias decretadas por el juez y nada dice respecto de impugnaciones de resoluciones relativas a diligencias probatorias. Por su parte, la letra l) del numeral $4^{\circ}$ del Auto Acordado establece la posibilidad del juzgador de decretar la realización de nuevas diligencias y de revisar vicios de procedimiento. No corresponde a esta Magistratura añadir preceptos a un Auto Acordado dictado por otro Tribunal, sino sólo declarar que los que existen son contrarios a la Constitución. Si declarara inconstitucional el señalado en la letra o) del número $4^{\circ}$, desaparecería el precepto que habilita a apelar las resoluciones definitivas y si lo hiciera con el de la letra l) de igual número, dejaría de existir el que consagra la posibilidad del juez de decretar nuevas diligencias o de corregir vicios de procedimiento. Si así obrara, el proceso que afecta a la requirente perdería en capacidad de impugnación y disminuiría su racionalidad y justicia. En consecuencia, debe rechazarse esta alegación de la requirente.

IV. Falta de competencia de la Corte para regular estas materias por medio de un Auto Acordado

VIGÉSIMO TERCERO. Que la requirente impugna la constitucionalidad del Auto Acordado por haber sido dictado por la Corte de Apelaciones, la que, según alega, carece de competencia para acordar normas con ese contenido, pues ni la Constitución ni la ley le atribuyen tal facultad; por lo que, al hacerlo, ha obrado fuera de su competencia y, con ello, vulnerado lo dispuesto en el artículo $7^{\circ}$ de la Carta Fundamental. 
Argumenta a este respecto que el Auto Acordado está dictado en virtud de la competencia que otorga el artículo $3^{\circ}$ del Código Orgánico de Tribunales, el que, según la requirente, le habilita sólo para ordenar los recursos o elementos para una mejor prestación del servicio judicial, debiendo reducirse su contenido a cuestiones del orden doméstico, interior o privado, al buen orden y funcionamiento, al mejor aprovechamiento de los medios y recursos humanos y materiales, pero no tiene competencia la Corte para regular o limitar derechos y garantías constitucionales, para establecer atribuciones o procedimientos o, de algún otro modo, reglamentar materias reservadas al legislador. Como puede apreciarse, este reproche se encuentra íntimamente vinculado con lo que se tratará en el capítulo siguiente, acerca de si las cuestiones reguladas por el Auto Acordado se encuentran o no reservadas al dominio legal. No obstante, cabe analizar aquí si una Corte de Apelaciones incurre en vicio de inconstitucionalidad al regular materias disciplinarias por estar ello más allá de su competencia.

VIGÉSIMO CUARTO. Que, desde luego, no cabe discutir la constitucionalidad de la competencia de una Corte de Apelaciones para dictar autos acordados. Si el artículo 93 $\mathrm{N}^{\circ} 2$ de la Carta Fundamental otorga a esta Magistratura competencia para revisar la constitucionalidad de estas normas, es evidente que valida esa competencia. Más aún, desde siempre se ha entendido que la capacidad para dictar autos acordados proviene de las facultades llamadas económicas que competen, en primer lugar, a la Corte Suprema, aunque también a las Cortes de Apelaciones. Esta facultad tiene igualmente consagración constitucional expresa en el artículo 82, precepto que viene repitiéndose en nuestras Cartas Fundamentales desde 1828. No existe definición constitucional acerca de qué sean las facultades económicas y cuál sea el ámbito de la competencia regulatoria otorgada en virtud de ellas. En la jerarquía legal, tampoco existe una delimitación del alcance de esta facultad, aunque algunos preceptos legales pueden ayudar a establecerlo. Así, el numeral $4^{\circ}$ del artículo 96 del Código Orgánico de Tribunales dispone que corresponde al Pleno de la Corte Suprema: " $4^{\circ}$ Ejercer las facultades administrativas, disciplinarias y económicas que las leyes le asignan, sin perjuicio de las que les correspondan a las salas en los asuntos de que estén conociendo, en conformidad a los artículos 542 y 543. En uso de tales facultades, podrá determinar la forma de funcionamiento de los tribunales y demás servicios judiciales, fijando los días y horas de trabajo en atención a las necesidades del servicio". Esta amplia referencia no permite determinar de manera precisa en qué consisten las facultades económicas, ya que, por una parte, la referencia es demasiado amplia: "forma de funcionamiento de los tribunales". El modo de proceder en materias disciplinarias es, sin duda, una forma de funcionamiento. Por el contrario, el ejemplo que emplea el precepto transcrito: fijar los días y horas de funcionamiento, es particular y reducido y alude a cuestiones administrativas internas. La ausencia de otros ejemplos impide conocer el alcance que el legislador le asigna a esta facultad. El reducido ámbito regulatorio que la requirente pretende asignarle a los autos acordados no se aviene con la tradición de las importantes cuestiones que, desde la época de la Colonia, la Real Audiencia primero y luego la Corte Suprema vienen regulando por medio de autos acordados. Es necesario entonces discernir, a nivel constitucional, el alcance de esta atribución. 
VIGÉSIMO QUINTO. Que la Constitución procura y consagra la independencia del Poder Judicial. Una de las dimensiones de tal independencia, además de la personal de cada juez, es la que debe tener el órgano judicial. Esta dimensión de la independencia resultaría imposible si la capacidad de autorregularse en su funcionamiento se redujera, como pretende la requirente, a puras cuestiones menores. La facultad disciplinaria es esencial a la prestación de un buen servicio judicial y, en este sentido, la vinculación entre las facultades disciplinarias y las económicas es evidente. La facultad disciplinaria de la Corte Suprema, incluso para remover o trasladar a jueces, le ha sido atribuida por la Constitución, en su artículo 80, mientras la facultad disciplinaria de la Corte de Apelaciones -incluida, por cierto, la de Santiago- se encuentra contemplada en los artículos 532 y siguientes, particularmente en el artículo 535, del Código Orgánico de Tribunales. Esta facultad disciplinaria, así consagrada en la Constitución y en la ley, está llamada a ejercerse. Tal ejercicio debe conformarse a la Constitución y a la ley. En aspectos de funcionamiento en que el legislador no ha establecido normas o que expresamente la Constitución no le ha reservado a éste, el propio órgano judicial puede auto regularse. Impedirlo haría imposible o enteramente discrecional el ejercicio de la facultad disciplinaria. Un Poder Judicial independiente y responsable de prestar un buen servicio a todas las personas, puede, a través de sus autoridades, regular el ejercicio de sus facultades disciplinarias por medio de autos acordados. Naturalmente estas regulaciones no pueden contradecir normas legales ni menos las de rango constitucional. Por ende, los autos acordados no pueden regular materias que el constituyente ha reservado al legislador. La requirente ha alegado que así sucede en el caso del impugnado, lo que se analizará en el acápite que sigue. Lo que se concluye en éste es que, en razón de la materia, la Corte de Apelaciones no ha violentado la Carta Fundamental por el hecho de regular el modo en que procederá para ejercer sus facultades disciplinarias. Las materias disciplinarias, en sí mismas, no presentan ninguna característica que impida su legítima regulación por auto acordado.

\section{El Auto Acordado y la reserva legal}

VIGÉSIMO SEXTO. Que, como ya se ha consignado, un cuarto reproche que dirige el requirente en contra del Auto Acordado consiste en que la Corte de Apelaciones de Santiago habría regulado materias que la Carta Fundamental reserva al legislador. Este reproche se afirma en varios fundamentos, el primero de los cuales se basa en lo dispuesto en el numeral 26 del artículo 19 de la Carta Fundamental. Conforme alega la requirente, el Auto Acordado regula derechos y garantías fundamentales. Para reforzar esta petición invoca también lo dispuesto en el artículo 63 de la Carta Fundamental, pues considera que el Auto Acordado estatuye las bases esenciales de un ordenamiento jurídico, y en el artículo 64 de la misma Carta, en cuanto prohíbe al legislador delegar en el Presidente de la República la regulación de materias comprendidas en las garantías constitucionales. 
VIGÉSIMO SÉPTIMO. Que los preceptos que cita la requirente efectivamente prohíben que órganos distintos y menos representativos y deliberativos que el legislador, regulen, complementen o limiten las garantías constitucionales. Lo que no resulta convincente es que los preceptos del Auto Acordado que pueden aplicarse a la requirente regulen, limiten o complementen derechos garantizados en la Constitución. En efecto, no se ve de qué modo podría concluirse que regula o limita un derecho fundamental un precepto como el contenido en la letra b) del numeral $4^{\circ}$ del Auto Acordado, que dispone que "la investigación se formará con todas las declaraciones, actuaciones y diligencias, a medida que se vayan sucediendo y con todos los documentos que se acompañen, pudiendo decretar de oficio las diligencias que se estimen convenientes". Tampoco regula o limita un derecho fundamental la regla del Auto Acordado que establece que "las notificaciones que se realicen en la indagación administrativa deberán hacerse personalmente". Tampoco los restantes preceptos aplicables limitan el ejercicio de garantías constitucionales. De esta conclusión se excluyen, desde luego, los preceptos que, en capítulos anteriores de esta misma sentencia, se han considerado, por razones diversas a la que ahora se examinan, contrarios a la Carta Fundamental. Por otra parte y conforme a lo razonado en el considerando $6^{\circ}$, este Tribunal no examinará este reproche respecto de otros preceptos contenidos en el Auto Acordado que no tengan la capacidad de afectar derechos de la requirente. En consecuencia, esta Magistratura no declarará inconstitucionales preceptos contenidos en el Auto Acordado por este concepto, por estimar que el reproche, dirigido genéricamente por la requirente en contra de todo el Auto Acordado, no alcanza preceptos que puedan afectarle y que sean distintos a los ya estimados inconstitucionales en razonamientos anteriores.

VIGÉSIMO OCTAVO. Que la requirente también ha fundado en el inciso quinto del numeral $3^{\circ}$ del artículo 19 de la Constitución, su reproche de que el Auto Acordado ha regulado materias reservadas al dominio legal, pues en ese precepto el constituyente ha dispuesto que toca únicamente al legislador establecer las reglas de un procedimiento y de una investigación racionales y justos. Refuerza este argumento en normas del Pacto de San José de Costa Rica. La norma constitucional invocada establece literalmente: "Toda sentencia de un órgano que ejerza jurisdicción debe fundarse en un proceso previo legalmente tramitado. Corresponderá al legislador establecer siempre las garantías de un procedimiento y de una investigación racionales y justos."

VIGÉSIMO NOVENO. Que es el legislador quien, en el Título XVI del Código Orgánico de Tribunales, ha establecido las normas que pudieran garantizar -o no hacerlo- un proceso racional y justo en materia de jurisdicción disciplinaria. Las reglas del Auto Acordado que son susceptibles de afectar los derechos de la requirente y que no sean aquellas respecto de las cuales ya se ha concluido que contravienen la Carta Fundamental, consisten en normas puramente reglamentarias de preceptos legales que no establecen un procedimiento, sino que se limitan a precisarlo en aspectos no esenciales, como los lugares en que deben practicarse las notificaciones, el modo en que debe formarse el expediente o el modo de contabilizarse ciertos plazos legales. En cuanto 
a la que fija el plazo para presentar descargos, contenido en la letra i) del artículo $4^{\circ}$, nos remitimos a lo razonado en el considerando 19. Si bien es cierto que algunas de las normas del Auto Acordado complementan reglas de procedimiento, aumentando la certeza de los funcionarios judiciales que participan o se ven afectados por estos procesos, no puede decirse que ellas sean ajenas al funcionamiento de la Corte de Apelaciones de Santiago o que esas normas reglamentarias contenidas en el Auto Acordado sean las llamadas a garantizar la justicia o racionalidad del procedimiento. El precepto constitucional invocado efectivamente reserva al legislador establecer las reglas procesales, de manera de garantizar que los procedimientos sean racionales y justos, pero ello no implica que los Tribunales Superiores de Justicia no puedan, en materias disciplinarias de su competencia, precisar su propio funcionamiento, dictando normas reglamentarias ante la falta de normas legales, a través de un auto acordado.

TRIGÉSIMO. Que, en tercer lugar, la requirente ha fundado que el Auto Acordado regula materias reservadas al legislador por estimar que ellas determinan la organización y atribuciones de los Tribunales de Justicia, lo que sólo puede hacer el legislador orgánico constitucional, conforme a lo dispuesto en el artículo 77 de la Constitución, conclusión que refuerza el artículo 63 de la misma Carta Fundamental. Por las razones expuestas en los considerandos 29 a 31 que anteceden, esta Magistratura concluye que las normas del Auto Acordado, diversas a aquella respecto de la cual ya se ha concluido que es inconstitucional y que puede afectar derechos fundamentales de la requirente, no otorgan atribuciones ni regulan la organización de los tribunales en aspectos que no estén ya contenidos en el Código Orgánico de Tribunales. En consecuencia, y por este motivo, no declarará la inconstitucionalidad de otros preceptos contenidos en el Auto Acordado.

(....)

VIII. Subsistencia de las restantes normas del Auto Acordado

TRIGÉSIMO CUARTO. Que la existencia del único precepto que se declarara inconstitucional conforme a los razonamientos anteriores no acarrea la necesidad de dejar sin efecto las restantes reglas contenidas en el Auto Acordado, las que tienen suficiente independencia y autonomía de la que debe quedar sin efecto para subsistir sin ella; todo ello, sin perjuicio de las facultades privativas de la Corte de Apelaciones de Santiago para modificar el Auto Acordado del que es autora.

Y VISTO lo dispuesto en los artículos $8^{\circ}$, inciso segundo, y $19 \mathrm{~N}^{\circ} 2$ y lo establecido en el artículo $93 \mathrm{~N}^{\circ} 2$ de la Constitución Política, y en la Ley $\mathrm{N}^{\circ} 17.997$, Orgánica Constitucional del Tribunal Constitucional, y demás normas citadas,

SE DECLARA que se acoge el requerimiento de inconstitucionalidad deducido a fojas 1 sólo en cuanto se declara inconstitucional lo prescrito en el numeral $4^{\circ}$, letra d), del "Auto Acordado Relativo al Procedimiento a Utilizarse para hacer Efectiva la 
Responsabilidad Disciplinaria de los Funcionarios y Empleados Judiciales”, dictado por la Corte de Apelaciones de Santiago y publicado en el Diario Oficial de 17 de noviembre de 1995 .

El Ministro señor Marcelo Venegas Palacios previene que concurre a la sentencia pero no suscribe sus considerandos $3^{\circ}$ al $8^{\circ}$, ambos inclusive.

La Ministra señora Marisol Peña Torres previene, asimismo, que concurre a la sentencia, pero que no comparte lo afirmado en los considerandos $8^{\circ}, 18^{\circ}$ y $21^{\circ}$, en el sentido que constatada la inconstitucionalidad de un precepto del Auto Acordado, en virtud de alguna de las razones invocadas por el requirente, se hace innecesario e inútil analizar otras causales de inconstitucionalidad alegadas respecto de la misma norma. Lo anterior, debido a que, a su juicio, tal forma de razonar no se compadece con la defensa integral del principio de supremacía constitucional que procura resguardar el control de constitucionalidad de la ley y de otros cuerpos jurídicos, como el impugnado en el presente procedimiento.

Acordada con el voto en contra del Ministro señor Enrique Navarro Beltrán, quien fue de opinión de rechazar el recurso de inconstitucionalidad teniendo presente las siguientes consideraciones:

1. Que se reprocha la constitucionalidad del Auto Acordado relativo al procedimiento a utilizarse para hacer efectiva la responsabilidad disciplinaria de los funcionarios y empleados judiciales, dictado en 1995 por la Corte de Apelaciones de Santiago, particularmente su letra d) del número $4^{\circ}$, conforme al cual "el sumario administrativo será reservado hasta la fecha de formulación de cargos, oportunidad en la cual dejará de serlo para el inculpado y para el abogado que asumiere su defensa";

2. Que la requirente estima que dicho precepto afectaría el debido proceso y el principio de la transparencia a que aluden los artículos $19 \mathrm{~N}^{\circ} 3$, inciso quinto, y $8^{\circ}$, inciso segundo, de la Constitución Política de la República;

3. Que la Corte de Apelaciones de Santiago, en su informe de fecha 30 de abril de 2007, expresa que el referido Auto Acordado se dictó -en uso de sus facultades económicas- frente a la ausencia de normas precisas que regularan la materia, de modo de establecer un procedimiento mínimo que pudiera salvaguardar los derechos básicos de los funcionarios judiciales, precisamente en cumplimiento de la garantía del debido proceso;

4. Que, como se sabe, el debido proceso se encuentra tutelado en el artículo $19 \mathrm{~N}^{\circ} 3$, inciso quinto, de la Constitución Política de la República, que garantiza el que "toda sentencia de un órgano que ejerza jurisdicción debe fundarse en un proceso previo legalmente tramitado", correspondiendo en todo caso al legislador "establecer siempre las garantías de un procedimiento y una investigación racionales y justos". Este Tribunal se ha encargado de precisar que entre los elementos fundamentales del debido proceso se deben destacar, entre otros, el conocimiento oportuno de la acción, la posibilidad de una adecuada defensa y la aportación de pruebas y el derecho a impugnar lo resuelto a través de un tribunal (Roles $\mathrm{N}^{\circ}$ s 478/2006 y 481/2006). Del mismo modo, se ha indicado que dichos principios resultan plenamente aplicables en materia administrativa sancionadora (Roles $\mathrm{N}^{\circ}$ s 244/1996, 437/2005 y 480/2006, entre otros); 
5. Que, a su turno, el inciso segundo del artículo $8^{\circ}$ de la Constitución Política de la República establece que "son públicos los actos y resoluciones de los órganos del Estado, así como sus fundamentos y los procedimientos que utilicen"; sin perjuicio de que pueda establecerse la reserva o secreto, en virtud de ley de quórum calificado, "cuando la publicidad afectare el debido cumplimiento de las funciones de dichos órganos, los derechos de las personas, la seguridad de la Nación o el interés nacional". Como lo ha señalado recientemente esta Magistratura, la publicidad de los actos de los órganos del Estado "constituye un soporte básico para el adecuado ejercicio y defensa de los derechos fundamentales de las personas que, eventualmente, puedan resultar lesionados como consecuencia de una actuación o de una omisión proveniente de los mismos" ( $\mathrm{Rol} \mathrm{N}^{\mathrm{0}} 434 / 2006,9$ de agosto de 2007, considerando $9^{\circ}$ );

6. Que en el caso de autos lo que se estima inconstitucional es la circunstancia de que el sumario administrativo que se instruyere al efecto sea reservado hasta la formulación de cargos, lo que sin embargo este disidente no estima en modo alguno contrario per se al debido proceso y al principio de publicidad, como se analizará;

7. Que, en efecto, por su propia naturaleza las primeras diligencias de toda investigación pueden tener el carácter de reservadas o secretas, habida consideración de que en muchos de los casos la denuncia puede carecer de toda base;

8. Que lo anterior se encuentra por lo demás íntimamente ligado a la dignidad de la persona, bien jurídico fundamental que resguarda ni más ni menos que el artículo $1^{\circ}$ de la Constitución Política de la República y que conforme a lo señalado por este Tribunal "es la cualidad del ser humano que lo hace acreedor siempre a un trato de respeto, porque ella es la fuente de los derechos esenciales y de las garantías destinadas a obtener que sean resguardados" ( $\mathrm{Rol} \mathrm{N} \mathrm{N}^{\circ} 389$, consid. $17^{\circ}$ ). De este modo, la dignidad de la persona humana importa el que la persona sea respetada en sí misma, "por el solo becho de serlo, con total independencia de sus atributos y capacidades" (Rol No 433, consid. $2^{\circ}$ ). En el mismo sentido, la doctrina ha puntualizado que "la dignidad exige siempre, o sea, sin excepciones, que el ser bumano sea tratado con respeto, lo cual no depende de sus atributos, capacidades, cualidades o defectos" (Miguel A. Fernández G., Los derechos fundamentales en 25 años de jurisprudencia del Tribunal Constitucional, Cuadernos del Tribunal Constitucional No 33, 2006, p. 31);

9. Que del mismo modo y en concordancia con la dignidad de la persona humana, la misma Carta Fundamental asegura a todas las personas, en su artículo $19 \mathrm{~N}^{\circ} 4$, "el respeto y protección a la vida privada y a la honra de la persona y su familia";

10. Que la reserva del sumario administrativo encuentra su fundamento en diversas disposiciones legales, las que en su caso deben considerarse como leyes de quórum calificado en los términos que establece el artículo $8^{\circ}$ de la Carta Fundamental. De esta forma, el inciso segundo del artículo 29 de la Ley de Procedimiento Administrativo $\mathrm{N}^{\circ} 19.880$ precisa que "con anterioridad al acuerdo de iniciación, podrá el órgano competente abrir un periodo de información previa con el fin de conocer las circunstancias del caso concreto y la conveniencia o no de iniciar el procedimiento". Por su parte el Estatuto Administrativo, Ley $\mathrm{N}^{\circ} 18.834$, en su artículo 137, inciso segundo, indica que "el sumario será secreto hasta la fecha de formulación de cargos, oportunidad en la cual 
dejará de serlo para el inculpado y para el abogado que asumiere su defensa", disposición idéntica a la del Auto Acordado que motiva el presente requerimiento. Ambos preceptos legales contienen principios que por lo demás resultan aplicables en la especie, habida consideración de que se trata de actuaciones de carácter administrativo y no jurisdiccional;

11. Que así las cosas, resulta evidente que el carácter reservado del sumario se encuentra íntimamente vinculado con la naturaleza de un proceso disciplinario, más aún si se tiene presente que a partir de la formulación de cargos surgen todos los derechos del inculpado para aportar pruebas y ejercer su defensa, lo que ciertamente se ha producido en el caso de autos, habida consideración de que la afectada ha tenido oportunidad para hacer valer sus alegaciones y rendir la prueba pertinente, en el marco de la investigación que fuera dirigida por el Ministro Visitador de la Corte de Apelaciones de Santiago, señor Juan Escobar Zepeda;

12. Que como puede apreciarse, en este caso concreto, la reserva de las diligencias preliminares encuentra su fundamento en la protección de los derechos de la persona afectada y en su dignidad, puesto que es perfectamente posible que los procesos que se inicien carezcan de toda base o fundamento;

13. Que, a mayor abundamiento, el presente requerimiento carece de efecto práctico desde el momento que la investigación se encuentra concluida, de modo que de estimarse inconstitucional, sus consecuencias serán inocuas en la gestión disciplinaria que se sigue, en los términos que preceptúa el artículo 94 de la Constitución Política de la República;

14. Que, por último, este disidente tiene también presente la circunstancia de que la Corte Suprema de Justicia ha dictado precisamente en estos días un Auto Acordado que regula expresamente el procedimiento en materia disciplinaria, como consecuencia de lo cual ha sido derogado el respectivo instructivo dictado en su momento por la Corte de Apelaciones de Santiago y que motivara el requerimiento de autos y que, específicamente sobre el punto, establece en su artículo $8^{\circ}$ que la eventual reserva de la investigación preliminar cesará transcurridos 30 días hábiles desde que se haya comunicado su apertura y aun antes si así lo resuelve el investigador, de oficio o a petición del denunciado.

Redactó la sentencia el Ministro señor Jorge Correa Sutil, y la disidencia su autor el Ministro señor Enrique Navarro Beltrán.

Publíquese la presente sentencia dentro de tercero día en el Diario Oficial, fecha desde la cual el precepto declarado inconstitucional debe entenderse derogado.

Notifíquese, regístrese y archívese.

Rol No 783-07.-

Pronunciada por el Excmo. Tribunal Constitucional, integrado por su Presidente (s) don José Luis Cea Egaña y los Ministros señores Raúl Bertelsen Repetto, Hernán Vodanovic Schnake, Mario Fernández Baeza, Jorge Correa Sutil, Marcelo Venegas Palacios, señora 
Marisol Peña Torres, Enrique Navarro Beltrán y Francisco Fernández Fredes. Autoriza el Secretario del Tribunal Constitucional, don Rafael Larraín Cruz.

\section{COMENTARio}

El día 31 de agosto el Tribunal Constitucional dictó, con un interesante trasfondo (disputa sobre compraventa de manifestaciones mineras circundantes al yacimiento de Pascua Lama en la III Región, véase pág. D. 20 de El Mercurio de 30.09.2007), sentencia en dos causas relacionadas: los roles 747 y 783 .

El rol 783 recae en la acción de inconstitucionalidad interpuesta por María Isabel Reyes Kokisch en contra del Auto Acordado Relativo al Procedimiento a Utilizarse para hacer Efectiva la Responsabilidad Disciplinaria de los Funcionarios y Empleados Judiciales, dictado el 13 de octubre de 1995 por la Corte de Apelaciones de Santiago y publicado en el Diario Oficial de 17 de noviembre de 1995 (en adelante, el Auto Acordado). Esta sentencia planta un hito histórico en dos ámbitos. Por una parte, es la primera vez que un auto acordado de tribunales superiores de justicia es controlado por un órgano ajeno a la superintendencia de la Corte Suprema y, al menos en una parte, es declarado inconstitucional. Por otra parte, es la primera vez que tiene lugar y se acoge una acción constitucional por afectación de derechos fundamentales ante el Tribunal Constitucional.

Es en este segundo aspecto donde se desprenden del fallo una serie de consecuencias gravitantes para el tratamiento de los derechos fundamentales en nuestra Constitución, comenzando por la circunstancia de que el Tribunal no discute, al menos en lo que expresa su sentencia, la admisibilidad de la acción desde la perspectiva de los requisitos del artículo 93 i. III CPR. En este punto es una lástima que, según da cuenta el propio fallo del Tribunal, la Corte de Apelaciones de Santiago no haya defendido la juridicidad de su propia producción normativa, el auto acordado atacado. Quizás por una errónea comprensión de la supremacía constitucional, la Corte se limita a señalar que "estará a lo que el Tribunal Constitucional resuelva sobre la materia", y renuncia de este modo a su propio e importante papel como intérprete-parte en el respectivo proceso constitucional. Pero el hecho es que se puede concluir, de esta ausencia de reflexión, que el Tribunal acepta sin más que la acción va enderezada contra un auto acordado que puede afectar los derechos fundamentales de la requirente. De este modo, el fallo resulta más importante en este punto por aquello que calla, que por lo que dice, a saber:

i.- se da por sentado que, a pesar de ser toda una innovación en nuestro lenguaje constitucional, la expresión "derechos fundamentales" que utiliza el art. 93 i. III CPR es coincidente con el ámbito que cubren los derechos constitucionales del artículo 19 de la Carta. La cuestión no es trivial tomando en cuenta la profusión de términos que utiliza nuestra Constitución en este campo (derechos de las personas, derechos esenciales que emanan de la naturaleza humana, derechos humanos, derechos constitucionales, libertades, derechos de los particulares, derechos fundamentales, garantías ) y el hecho de que en la doctrina existen al menos tres, 
sino más posibilidades de entender los derechos fundamentales. Dentro de estas alternativas, aquella que es propia del derecho comparado y que implica la denominación positiva de los respectivos derechos constitucionales como "Derechos Fundamentales” (Ley Fundamental de Bonn, I; Constitución de España Título I, Constitución de Brasil Título II, Constitución de Colombia Título II capítulo I, etc.) no se da en nuestra Constitución, que los llama "Derechos Constitucionales" (Cap. III). Ante esto, no resultaba obvio el sentido que debía atribuirse a esta expresión, y podía haberse esperado una reflexión del Tribunal al respecto;

ii.- se asimila todo precepto dentro del artículo 19 CPR a la noción de derecho fundamental, incluso en aquellos casos donde la redacción de la propia Constitución no da lugar para asumir el reconocimiento de un derecho como tal. Y esto porque la sentencia discurre en reiteradas oportunidades sobre el alegato de la lesión del "derecho" a un justo y racional procedimiento que hace valer la parte requirente. Sin embargo, si se lee con atención el artículo $19 \mathrm{~N}^{0} 3$ i. V de la Carta, se observa que no existe tal derecho, sino que un deber dirigido al legislador. De lo anterior se desprende, entonces, que al Tribunal no le ha parecido relevante distinguir entre “derechos" y otros preceptos que, ubicados en el artículo 19 de la Constitución, no establezcan derechos sino deberes de actuación estatal;

iii.- en tercer lugar, el tribunal interpreta de manera amplia el concepto de "afectación”. Según se desprende del voto de minoría del ministro Enrique Navarro Beltrán (que no de los antecedentes, que no he tenido la oportunidad de conocer), a la fecha del pronunciamiento del Tribunal la investigación, sobre la que incidía el precepto que se suponía afectando al derecho fundamental a un justo y racional procedimiento, se encontraba cerrada; la acción devenía en intrascendente para salir al paso de la afectación de un derecho fundamental. El Tribunal no dispone -no tiene facultades para ello-, ni se ve cómo podría producirse, la nulidad de lo ya obrado en el respectivo procedimiento De este modo, el pronunciamiento del Tribunal no toma como relevante la posibilidad de lesión concreta que la norma impugnada puede producir al derecho afectado, sino que le basta la consideración, in abstracto, de su inconstitucionalidad;

iv.- por último, es interesante destacar que la causa que motiva la declaración de inconstitucionalidad no es el precepto (diríamos, de derecho objetivo) correspondiente al derecho fundamental (subjetivo) alegado, sino una disposición distinta, como lo es el art. $8^{\circ} \mathrm{CPR}$ en lo referente al principio de publicidad. El Tribunal constata en su considerando 17 la contradicción entre el numeral $4^{\circ}$ letra d) del auto acordado y el art. $8^{\circ}$ de la Constitución, y en el considerando 18 señala que no estima necesario analizar otros vicios de inconstitucionalidad que pudiesen afectar a dicha disposición. De este modo, resulta del fallo en rol 783 que el Tribunal no estima necesario que exista conexión entre la afectación del derecho alegada por la parte requirente y el específico motivo de inconstitucionalidad en virtud del cual se pronuncia sobre la inconstitucionalidad del respectivo auto acordado.

Si llevamos a una expresión positiva los criterios que se desprenden de la ausencia de toda consideración sobre estos puntos, puede concluirse de este fallo que, para el Tribunal 
Constitucional, la expresión "derechos fundamentales" del art 93 i III de la Carta comprende al menos, y sin discusión, todo el contenido de su art. 19, sin distinción de si la fórmula normativa se expresa en términos de derechos subjetivos o de deberes estatales; que el concepto de afectación no se encuentra sometido a una exigencia de efectividad de la lesión, o principio de trascendencia, sino simplemente de la contradicción normativa con la Constitución, y que esta contradicción no se circunscribe a la infracción por parte del respectivo auto acordado de un precepto de derecho fundamental, sino que de cualquier precepto constitucional que entre en conexión con el razonamiento asociado al derecho fundamental invocado.

Fuera de estas conclusiones, que me parece se desprenden claramente del fallo, queda abierta en esta decisión una cuestión de importancia para el tema de los derechos fundamentales. En un sentido cercano a la prevención de la ministra Marisol Peña Torres sobre la falta de pronunciamiento del Tribunal sobre todos los argumentos de inconstitucionalidad hechos valer por la requirente, es particularmente notable la absoluta falta de pronunciamiento e incluso de consideración, por parte del Tribunal, respecto de las permanentes alegaciones sobre la base de la Convención Americana de Derechos Humanos, Pacto de San José de Costa Rica, que hace la requirente. Y digo que es notable porque, siendo la primera vez que el Tribunal se pronunciaba sobre una acción de amparo constitucional de derechos, hubiese sido deseable delimitar el campo de futuras acciones vía art. 93 i. I No 2 - art. 93 i. III CPR. La decisión en el rol 346, si bien rechaza la tesis de la jerarquía normativa constitucional de los tratados internacionales en materia de derechos de las personas, no aporta nada a la cuestión de cómo un alegato sobre la bases de derechos contemplados en dichos tratados debe manejarse a la luz del deber contenido en el art. $5^{\circ}$ i. II de la Constitución. La cuestión se torna especialmente delicada si consideramos la forma en la que el Tribunal enfrenta el tema conceptual, en lo relativo a derechos fundamentales. ¿Puede darse a éstos, a la luz del art. $5^{\circ}$ mencionado, y dada la diferencia terminológica con el art. 19 CPR, un alcance más amplio que el de derechos constitucionales, e incluir dentro de aquellos, por ejemplo, a los derechos contenidos en el Pacto de San José de Costa Rica, y otros? El Tribunal pudo -y estimo que debió, dado su carácter de principal fundamento de las peticiones de la actora- haberse pronunciado sobre el punto, amojonando aquí el terreno conceptual y procesal de futuras acciones. Sin embargo, el campo quedó abierto. 